\title{
Senescent human diploid fibroblasts are able to support DNA synthesis and to express markers associated with proliferation
}

\author{
IAN R. KILL* and SYDNEY SHALL \\ Laboratory of Cell and Molecular Biology, School of Biological Sciences, Biology Buildıng, University of Sussex, Brighton BNI 9QG, \\ England \\ * Author for correspondence \\ Present address: Department of Biological Sciences, The University, Dundee DD1 4HN, Scotland
}

\section{Summary}

The characteristic limited reproductive life-span of normal human fibroblasts in culture is due to a steadily decreasing fraction of cells able to proliferate in the standard rich growth media. We have observed that restricting the growth factor supply to old cells for variable lengths of time in culture increases the fraction of cells that can enter S-phase; although these cells do not go on to divide. Thus, it seems that there is a transient phase between the proliferating state and the irreversibly post-mitotic,

senescent state. Perhaps a 'quiescent- $G_{0}$ ' state, which can be maintained in the presence of growth factors, is a stage on the pathway to mortalization and senescence.

Key words: human fibroblasts, limited lifespan, Hayflick limit, mortalization, growth-regulation, cell senescence, DNA synthesis.

\section{Introduction}

The growth of normal human diploid fibroblasts is characterised by a finite and predictable lifespan (Hayflick and Moorehead, 1961; Shall, 1987). The limited lifespan is due to a steadily decreasing fraction of proliferating cells (Smith and Hayflick, 1974; Westermark, 1978; Stein et al. 1978; Stein and Shall, 1978; Shall and Stein, 1979; Ponten et al. 1983). This widely studied example of cell growth regulation is poorly understood at the molecular level. In aged cultures only a small proportion of cells incorporate nucleotides or their analogues into DNA (Cristofalo and Sharf, 1973). To determine whether senescent cells do sense growth factor signals, Paulsson et al. (1986) and Rittling et al. (1986), made senescent cells serum-starved by incubation in low serum for 48 and $40 \mathrm{~h}$, respectively. Restimulation of these ' $\mathrm{G}_{0}$ ' cells with growth factors or with serum resulted in the expression of the immediateearly, early, mid- $G_{1}$ and late- $G_{1}$ genes in these cultures. Therefore, it was suggested that this inability to proliferate is due to a 'downstream' block, either very late in $\mathrm{G}_{1}$ (Paulsson et al. 1986), or early in S (Rittling et al. 1986), and is not due to an inability to sense and/or to respond to growth signals. However, their conclusion must be reexamined because we report here that quite unexpectedly, serum-starved, senescent cells that were not proliferating previously, can be induced to proceed through $G_{1}$ and to enter $S$ phase and $G_{2}$.

Thus, it appears that there is a transient phase between the proliferating state and the irreversibly post-mitotic, senescent state. Perhaps, a 'quiescent- $G_{0}$ ' state that can be maintained in the presence of growth factors, is a stage on the pathway to mortalization and senescence.

Journal of Cell Science 97, 473-478 (1990)

Printed in Great Britain (C) The Company of Biologists Limited 1990

\section{Materials and methods}

\section{Cell culture}

Adult human dermal fibroblasts (strain 1BR.3) were obtained from a punch biopsy (Arlett et al. 1975). The cells were grown in Dulbecco's modification of Eagle's medium (DMEM) supplemented with $10 \%(\mathrm{v} / \mathrm{v})$ newborn calf serum (NCS) and antibiotics (10 units ml ${ }^{-1}$ of penicillin, $50 \mu \mathrm{g} \mathrm{ml}^{-1}$ of streptomycin) to the 27 th passage, at which time the culture had undergone 65 accumulated population doublings. Senescent cells were plated onto $13 \mathrm{~mm}$ diameter glass coverslips at a density of $3 \times 10^{3}$ cells cm${ }^{-2}$. Cell cultures were maintained in DMEM supplemented with $10 \%$ (v/v) NCS and antibiotics for 2 days, then washed twice in DMEM, and finally refed with DMEM supplemented with $0.5 \%$ (v/v) NCS and antibiotics. After 2,7 or 14 days, cultures were refed with DMEM supplemented with $10 \%$ (v/v) NCS and antibiotics. Control cultures were maintained in $10 \%(\mathrm{v} / \mathrm{v})$ NCS continuously.

\section{Detection of DNA synthesis}

To detect DNA synthesis, cells on coverslips were incubated with $25 \mu \mathrm{M} 5$-bromodeoxyuridine in the presence of $2 \mu \mathrm{M}$ fluorodeoxyuridine to inhibit thymidylate synthetase (Gratzner, 1982), at various times and durations following serum restimulation. Cells were washed twice with PBS and then fixed with $3.7 \%$ formaldehyde in PBS for $10 \mathrm{~min}$ at room temperature. Cells were then washed twice in PBS, treated with $1.5 \mathrm{M} \mathrm{HCl}$ for $30 \mathrm{~min}$ at room temperature to denature the DNA and washed extensively with PBS. Cells were covered with $10 \mu \mathrm{l}$ of a rat monoclonal antibody raised against 5-bromodeoxyuridine (1:10 in PBS/FCS Sera-Labs) and incubated for $1 \mathrm{~h}$ at room temperature or overnight at $4^{\circ} \mathrm{C}$ in a humidified atmosphere. In all the experiments described in this paper, the antibody solutions were made up in PBS containing $1 \%(\mathrm{v} / \mathrm{v})$ foetal calf serum (FCS); this mixture is called PBS/FCS in all procedures. After washing, a fluorescein-conjugated rabbit anti-rat antibody (1:30 in PBS/ 
FCS) was added and the cells were incubated for a further $1 \mathrm{~h}$ at room temperature. After washing, coverslips were mounted in $50 \%$ glycerol in $50 \mathrm{~mm}$ Tris- $\mathrm{HCl}\left(\mathrm{pH} 8.0\right.$ ) containing $1 \mu \mathrm{g} \mathrm{ml}^{-1}$ 4,6-diamidino-2-phenylindole (DAPI) and $1 \mathrm{mg} \mathrm{m}^{-1}$ $p$-phenylenediamine, and sealed with nail polish. Stained cells were viewed with a Zeiss Photomicroscope III fitted with a $63 \times$ water-immersion objective using epifluorescence. For assessment of the proportion of stained cells, 1000 total or 200 positive nuclei were counted in randomly selected fields.

\section{Detection of proliferation-associated antigens}

At 24 and at $48 \mathrm{~h}$ following serum restimulation, cells on coverslips were washed twice with PBS and fixed with methanol/ acetone $(1: 1, \mathrm{v} / \mathrm{v})$ for $10 \mathrm{~min}$ at $4^{\circ} \mathrm{C}$, then they were rehydrated, washed with PBS and covered with $10 \mu \mathrm{l}$ of one of the following antibody solutions: Ki-67 (1:50, in PBS/FCS); anti-PCNA (1:1000 in PBS/FCS, a kind gift from Dr R. Bravo, EMBL, Heldelberg); anti-topoisomerase II (1:250 in PBS/FCS, a kind gift from Dr L. Liu, Johns Hopkins University School of Medicine, Baltimore). The cells were incubated for $1 \mathrm{~h}$ at room temperature or overnight at $4^{\circ} \mathrm{C}$ in a humidified atmosphere, and were then washed with PBS and covered with $10 \mu \mathrm{l}$ of one of the following second antibody solutions: for $\mathrm{Ki}-67$, flourescein-conjugated rabbit anti-mouse IgG (1:20 in PBS/FCS); for PCNA, rhodamine-conjugated goat antihuman IgG (1:25 in PBS/FCS); for topoisomerase II, fluoresceinconjugated swine anti-rabbit IgG (1:40 in PBS/FCS). After $1 \mathrm{~h}$ at room temperature in a humidified atmosphere the cells were washed with PBS, mounted and scored, as described above.

\section{Increase in cell number}

Control cultures at passage 27 were plated onto $35 \mathrm{~mm}$ dishes at about $2.1 \times 10^{4}$ cells/dish and maintained in medium containing $10 \% \operatorname{NCS}(\mathrm{v} / \mathrm{v})$ for 2 days. Two dishes were harvested for determining cell number (day 0 ), and the remaining dishes were kept for a further 7 days when they were harvested for cell counting (day 7). Treated cultures at passage 27 were plated onto $35 \mathrm{~mm}$ dishes at about $2.1 \times 10^{4}$ cells/dish and maintained in medium containing $10 \% \operatorname{NCS}(\mathrm{v} / \mathrm{v})$ for 2 days, then washed twice in serum-free medium, refed with medium containing $0.5 \%$ NCS (v/v), and incubated at $37^{\circ} \mathrm{C}$ in $5 \%$ carbon dioxide:air for 7 days. The medium was replaced with fresh medium containing $10 \%$ (v/v) NCS and two dishes were harvested for cell counting (day 0 ). The remaining dishes were maintained in medium with $10 \%$ NCS $(v / v)$ for a further 7 days, when they were harvested for cell counting (day 7).

For estimation of cell numbers, four independent estimations on each duplicate sample were made, using a Coulter counter.

\section{Results}

\section{Synthesis of DNA by 'senescent' human diploid} fibroblasts

We are interested in defining the molecular mechanism of the block to proliferation in senescent cultures. We asked whether the ability of senescent cells to respond to growth factors included traverse through $\mathrm{S}$-phase and $\mathrm{G}_{2}$. We therefore determined the fraction of senescent cells that were able to incorporate the thymidine analogue, 5-bromodeoxyuridine (BrdUrd), following serum stimulation of serum-starved cells induced by a 2-day, a 7-day or a 14-day period in low serum (Table 1, A). Human dermal fibroblasts were serially passaged in medium containing $10 \%$ serum for 65 accumulated population doublings. Fewer than $5 \%$ of these cells were then incorporating BrdUrd in a $48 \mathrm{~h}$ continuous exposure, indicating that the culture was moderately senescent. Following a 2-day period of low serum, after re-stimulation with serum, $12.2 \%$ of cells incorporated BrdUrd during the first $24 \mathrm{~h}$; however, this increased to $14.1 \%$ over $48 \mathrm{~h}$. Thus, rather
Table 1. Percentage of senescent, serum-starved, human diploid cells synthesising DNA following serum stimulation

\begin{tabular}{lcccr}
\hline & \multicolumn{4}{c}{$\begin{array}{c}\text { Time of exposure to BrdUrd } \\
\text { (h following stimulation) }\end{array}$} \\
\cline { 2 - 5 } & $0-24$ & $24-48$ & $0-48$ & $47.5-48$ \\
\hline $\begin{array}{l}\text { A. Experiment 1 } \\
\text { (a) Control culture }\end{array}$ & n.d. & n.d. & 4.0 & n.d. \\
$\quad$ Serum starvation: & & & & \\
$\begin{array}{l}\text { (b) 2 days } \\
\text { (c) 7 days }\end{array}$ & 12.2 & 6.5 & 14.1 & 1.7 \\
(d) 14 days & 141 & 23.9 & 28.5 & 2.8 \\
B. Experiment 2 & 15.0 & 29.1 & 32.2 & 5.0 \\
(a) Control culture & & & & \\
$\quad$ Serum starvation: & n d. & n.d. & 3.5 & n.d. \\
(b) 2 days & & & & \\
(c) 7 days & 2.2 & 13.3 & 12.6 & $<1.0$ \\
\end{tabular}

Control cultures (a) were maintained in $10 \%$ NCS (v/v) continuously. After 2 days (b); 7 days (c) or 14 days (d), the cultures were refed with DMEM, supplemented with $10 \%$ (v/v) NCS and antibiotics. Less than $1.0 \%$ of cells in parallel cultures maintained in DMEM supplemented with $0.5 \%(v / v)$ NCS throughout the $48 \mathrm{~h}$ exposure to BrdUrd were labelled. n.d., not determined.

unexpectedly, over 3.5 times more senescent cells can be induced to enter $S$-phase by this procedure than occurs in non-serum-starved cultures. A 30 min exposure to BrdUrd at $48 \mathrm{~h}$ indicated that synthesis had almost ceased by this time. More surprisingly, after a longer period ( 7 days) of serum starvation, there were over seven times more cells entering S-phase $(28.5 \%)$ following restimulation with serum than were observed in the control cultures. Increasing the period spent under conditions of low serum to 14 days resulted in an 8 -fold increase in the fraction of cells entering S-phase $(32.2 \%)$ following restimulation with serum than were observed in the control cultures.

In the second experiment, we again determined the fraction of cells able to synthesise DNA following 2 and 7 days spent under conditions of low serum, followed by restimulation with serum (Table $1, B$ ). Again, we found that by treating cultures with low serum followed by restimulation with high levels of serum, more cells were able to synthesise DNA than in untreated cultures. In cultures maintained in low serum for 2 days, and then restimulated, over 3.5 times more cells had entered S-phase by $48 \mathrm{~h}$ than in control cultures. The fraction of cells synthesising DNA had increased 8-fold after $48 \mathrm{~h}$ of restimulation in cultures that had been kept in low serum for 7 days, compared to the control cultures.

Expression of antigens commonly associated with proliferating cells by serum-starved, senescent, human diploid fibroblasts

To confirm this result, we determined the fraction of cells that expressed antigens commonly associated with proliferating cells in parallel cultures treated in an identical manner (Table 2).

Proliferating cell nuclear antigen (PCNA) (Bravo et al. 1987 ) is an auxiliary protein of DNA polymerase delta and has been shown to be involved in DNA synthesis (Prelich and Stillman, 1988). Only cells actively engaged in DNA synthesis at the time of fixation react with the PCNA antibodies used in this study, when methanol/acetone is used as the fixative (Bravo and MacDonald-Bravo, 1987). Topoisomerase II (Topo II) is a well-characterised nuclear enzyme, involved both in DNA replication (Yang et al. 
Table 2. Percentage of senescent, serum-starved, human diploid cells expressing antigens, usually associated with cell proliferation, following serum stimulation

\begin{tabular}{lccr}
\hline \multirow{2}{*}{$\begin{array}{l}\text { Time after } \\
\text { restimulation } \\
\text { (h) }\end{array}$} & \multicolumn{3}{c}{ Antigen } \\
\cline { 2 - 4 } & $\begin{array}{c}\text { Topoisomerase } \\
\text { II }\end{array}$ & PCNA & Ki-67 \\
\hline (a) Control culture & $<1.0$ & $<1.0$ & 4.5 \\
(b) 2-day serum starvation & & & \\
$0 \mathrm{~h}$ & $<1.0$ & $<1.0$ & $<10$ \\
$24 \mathrm{~h}$ & 4.6 & 3.0 & 4.5 \\
$48 \mathrm{~h}$ & 2.0 & 2.3 & 10.8 \\
(c) 7-day serum starvation & & & \\
0h & $<1.0$ & $<1.0$ & $<1.0$ \\
$24 \mathrm{~h}$ & 13.4 & 13.4 & 14.2 \\
$48 \mathrm{~h}$ & 88 & 2.9 & 22.0
\end{tabular}

The cells were cultured, serum starved and restimulated as described in Materials and methods. At 0,24 and $48 \mathrm{~h}$ following serum stimulation, the cells were fixed and stained. The fraction of cells expressing each antigen was determined by counting 1000 total or 200 positive nuclei in randomly selected fields.

1987) and in the segregation of replicated DNA molecules (DiNardo et al. 1984; Uemura and Yanagida, 1984; Earnshaw and Heck, 1985). Ki-67 is a poorly characterised nuclear antigen of unknown function, found only in proliferating human cells (Gerdes et al. 1983). The antigens are displayed in Fig. 1. In senescent, control cultures maintained in medium supplemented with $10 \%$ $(\mathrm{v} / \mathrm{v})$ serum, the fraction of cells expressing any one of the three antigens was low $(<0.045)$. Restimulation of serumstarved, senescent cells again resulted in the unexpected observation that more cells displayed the proliferation antigens than in the control cultures (Table 2). After 2 days of serum starvation, 3 - to 4 -fold more cells displayed these antigens than did the control cultures. After 7 days of serum starvation, re-stimulation induced expression of these proliferation antigens in six to over 13 times more cells than in control cultures: Topo II and PCNA showed highest at about $24 \mathrm{~h}$, while Ki-67 expression was most frequent at around $48 \mathrm{~h}$. Paulsson et al. (1986) determined the percentage of cells expressing $\mathrm{Ki}-67$ at $24 \mathrm{~h}$ following serum or PDGF stimulation of senescent human fibroblasts that had been kept in $0.5 \%$ serum for 2 days. They reported levels of expression similar to those shown in this paper; however, we found that expression was even more frequent at $48 \mathrm{~h}$.

\section{Cell division in restimulated cultures}

To determine the fraction of cells that not only traversed $\mathrm{S}$ and $\mathrm{G}_{2}$ but also divided, following restimulation of cultures that had been kept in low serum for 7 days, we estimated the percentage increase in cell numbers after 7 days following restimulation (Table 3 ).

In the treated cultures, the increase in cell numbers was $12.9 \%$ over a 7 -day period following restimulation. In a separate experiment we found that cultures of a similar age kept in high levels of serum continuously showed a $6.0 \%$ increase in cell number over a 7-day period. In addition, we found that $7.5 \%$ of the cells in a parallel, control culture were able to synthesise DNA over the same 7-day period, as determined by autoradiography of cultures grown in medium supplemented with $0.5 \mu \mathrm{Ci} \mathrm{ml} l^{-1}$ of $\left[{ }^{3} \mathrm{H}\right]$ thymidine (data not shown). Thus, although serum starvation appears to double the fraction of cells that are able to divide compared with untreated cultures, following the same treatment does not induce the same fraction of cells to divide $(12.9 \%$, Table 3$)$ as are able to synthesise DNA (28.5\%, Table $1 \mathrm{~A}$, experiment $1(\mathrm{c})$ ).

We have compared the estimates of the fraction of S-phase cells derived from BrdUrd incorporation and from PCNA antibody identification (Tables 1 and 2). In both the 2-day and the 7-day serum starvation experiments, we note that the BrdUrd incorporation shows a much higher fraction of cells over both 24 and $48 \mathrm{~h}$, than is observed with the PCNA estimation at 24 or at $48 \mathrm{~h}$. Of course, this is due to the fact that the BrdUrd measures incorporation over 24 or $48 \mathrm{~h}$, while the PCNA estimate is an instantaneous measure. However, comparison of estimates derived from the BrdUrd incorporation for $30 \mathrm{~min}$ at $48 \mathrm{~h}$ with the PCNA estimate at $48 \mathrm{~h}$ shows that the PCNA estimate is consistently slightly higher than the BrdUrd estimate. These small differences are probably a reflection of the relative sensitivities of the two, rather different, techniques.

\section{Discussion}

These data show that following a short (2 day) period in low serum, a much larger fraction of cells in senescent cultures were able to support DNA synthesis and to express markers associated with proliferation than is seen in control, untreated senescent cultures. Extending the period of serum starvation from 2 to 7 days, results in a 6to 13 -fold increase in the fraction of cells synthesising DNA and expressing these proliferation markers. Extending the period of serum starvation from 7 to 14 days only slightly increases the fraction of cells able to synthesise DNA (7-fold to 8-fold). Thus, while apparently senescent human cells can be induced to enter $S$ phase and $G_{2}$, not all the senescent cells in the culture enter the cell cycle. The low-serum treatment apparently induces more cells to divide (about 13\%, Table 3) than do so in a comparable untreated culture (about 6\%, Table 3), but not to the extent predicted by the fraction of cells that were able to synthesise DNA following the same treatment (about $29 \%$, Table $1 \mathrm{~A}$, experiment $1(\mathrm{c})$ ). This result suggests that at least some cells that are able to synthesise DNA remain blocked with regard to proliferation at a point in or beyond S-phase; the antigen Ki-67 is positive and PCNA is negative, and this combination of antigens strongly suggests that the cells have passed through the S-phase and are now in $\mathrm{G}_{2}$. A note of caution, however, is required because the cell numbers involved were rather small.

The available data argue against the possibility that our results are due to a partial synchronization of the culture by the experimental procedure. For example, it has been shown that the average duration of the cell cycle increases only slightly during in vitro ageing (Westermark, 1978; Macieira-Coelho et al. 1966; Grove and Cristofalo, 1976; Ponten et al. 1983). Therefore, it is highly unlikely that our results are due to a partial synchronisation of the culture by the serum starvation treatment because the average duration of the cell cycle in aged cultures is only about double (approximately 2 days) that of young cultures (about 1 day). Almost all cells capable of synthesising DNA under control conditions should become labelled in a $48 \mathrm{~h}$ continuous exposure to BrdUrd. Therefore, it would require cell cycle times 6- to 13-fold longer to explain our results in this way, because we observe an increase of this magnitude in the fraction of cells that enter S-phase after serum starvation. Further- 
more, we can exclude partial synchronization because only $20 \%$ of the cells that enter S-phase go on to divide, whereas we would expect all the cells synthesising DNA to divide within the 7-day period allowed for passage from S-phase to cell division.

Cellular proliferation is regulated by a complex interaction of positively and negatively acting factors (Vogel $e t a l$. 1978; Inglot et al. 1980). Recent reports (Brooks and Riddle, 1988; Loo et al. 1987) have implicated the serum supplement of normal growth media as a source of both classes of factors. Aged cultures maintained in high levels of serum are apparently unable to respond fully to the mitogenic factors which are present, since they contain a fraction of cells that are unable to synthesise DNA or to express certain markers usually associated with proliferation. In contrast, young cultures grown under the same conditions are able to respond more fully to the same
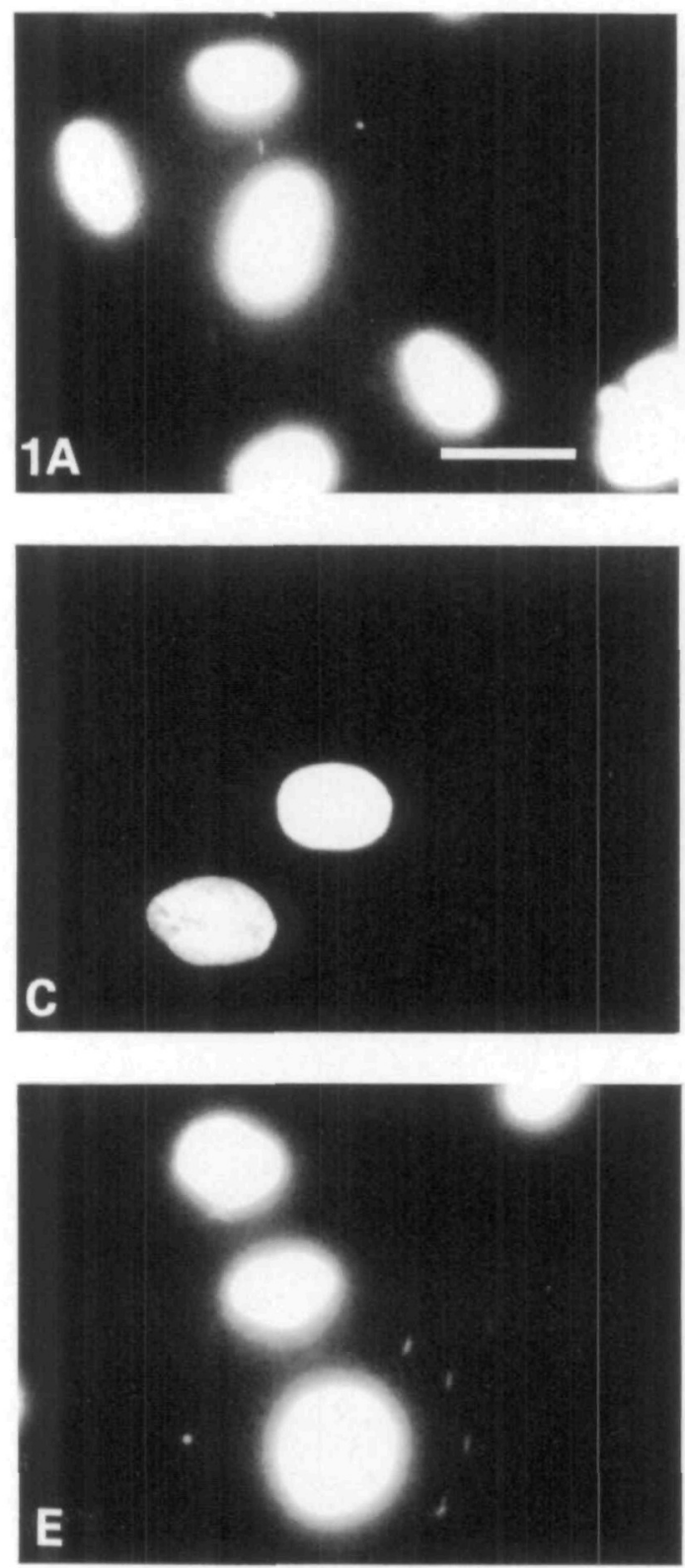

factors. Thus, it seems that these cells are changing their ability to respond to mitogenic factors with time in culture. However, a greater percentage of cells respond to stimulating factors upon readdition of high levels of serum to cultures treated with low serum, when compared to replicate cultures maintained in high serum continuously. This implies that the low serum treatment induces a change in responsiveness in a demonstrable population of cells. We suggest that this change may be due to an increased responsiveness to growth-promoting factors and/or a decreased responsiveness to growth-inhibiting factors.

One possible explanation of these results may be provided by the work of Collins and Rozengurt (1984a; 1984b), who have demonstrated down-regulation of growth factor receptors by treatment with apparently unrelated growth factors. Thus, removal of certain growth
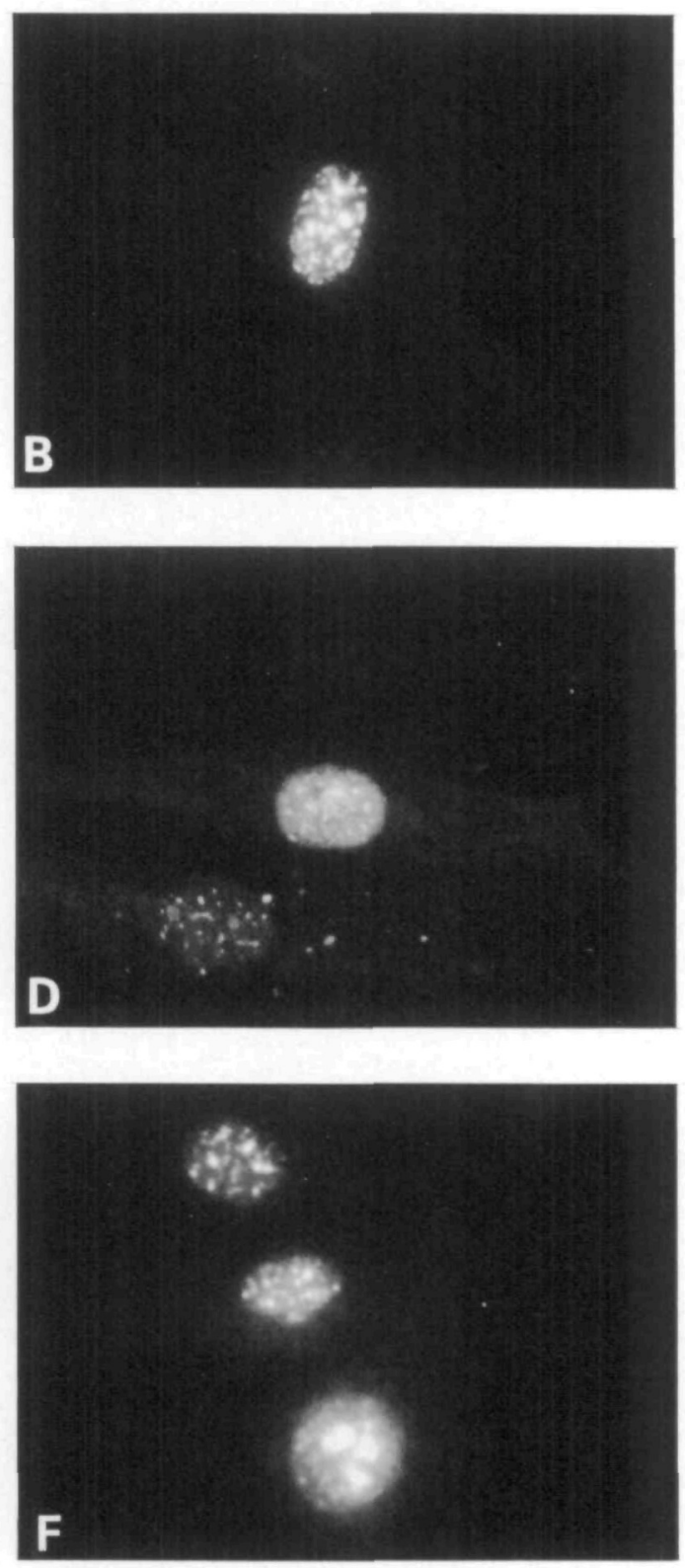

Fig. 1. Proliferation-associated antigens in senescent human cells. The figure shows fluorescence patterns observed with antibodies to: (B) PCNA, (D) topoisomerase II, (F) and Ki-67. The identical fields in each case stained with DAPI are shown in A, C and E. All photomicrographs were taken at the same magnification. Bar $=10 \mu \mathrm{m}$. 
Table 3. Cell number increase during 7 days following serum restimulation of senescent, serum-starved, human, diploid fibroblasts

\begin{tabular}{lccc}
\hline & \multicolumn{2}{c}{$\begin{array}{c}\text { Mean cell number } \\
( \pm \text { S.E.M }\end{array}$} & $n=8)$ \\
\cline { 2 - 4 } & Day 0 & Day 7 & $\begin{array}{c}\text { Mean } \\
\text { increase } \\
(\%)\end{array}$ \\
\hline (a) Control culture & $24848 \pm 60$ & $26350 \pm 27$ & 6.0 \\
(b) 7-day serum-starved & $19869 \pm 143$ & $22439 \pm 59$ & 12.9
\end{tabular}

Control cultures (a) and treated cultures (b) were derived from the cells described in the legend to Table 1 . The treated cultures were derived from the same cell stocks as described in Table 1, Experiment 1. The control cultures were derived from parallel cell stocks passaged on the same day as the treated cultures.

factors may lead to the reappearance of other unrelated growth factor receptors. Perhaps culture of human, mortal cells continuously in high levels of serum leads to downregulation of growth factor receptors by growth factors present in serum. This may result in a reduced responsiveness to the growth-promoting effects of growth factors. Eventually, aged cultures would contain a high proportion of cells with a reduced responsiveness to growth factors, due to the down-regulation of growth factor receptors. Treatment of these aged cultures with low serum may reduce the concentration of growth factors leading to a reappearance of the growth factor receptors. Those cells responding to the low serum treatment by synthesising growth factor receptors would show an increased response to the growth-promoting factors upon the re-addition of high levels of serum.

Alternatively, the phenomena that we have observed may be due to the behaviour of growth control genes. For example, we have observed that apparently senescent human cells may be blocked in either the $G_{1}$ or the $G_{2}$ phase of the cell cycle. This growth behaviour is strongly reminiscent of the properties of the gene coding for the protein kinase known as pp34-cdc2. Mutations in this gene in yeast are able to arrest cells in both these phases of the cell cycle; thus, we can imagine that this protein kinase may be responsible for initially blocking the senescent cells in $G_{1}$, and then at a later time, this kinase may be associated with a subsequent block in late $\mathrm{G}_{2}$.

Since the greater proportion of cells in aged cultures still do not respond to serum, even following prolonged treatment with low serum, then this may define the true, distinct, senescent state. We would therefore suggest that perhaps cells continue to cycle in response to growthpromoting factors until they enter a particular state in which they have ceased proliferating, but are not yet irreversibly mortalised, that is, reproductively sterile. Entry into this state may be due to some alteration in the responsiveness of those cells to growth factors. Furthermore, this state may only be demonstrated by the ability of cells to respond to growth factors after treatment with low serum. Eventually, under conditions of high $(10 \%(\mathrm{v} / \mathrm{v}))$ serum concentration, this fraction of cells will enter a true senescent state, defined by their inability to re-enter the cell cycle, even after a period spent at a low serum level. Thus, we may propose that cells may enter an intermediate senescent state, maintained in the presence of growth factors, which may be a stage on the pathway to mortalisation and senescence.

We thank the SERC for an instant studentship to I.R.K. We also thank Drs R. Brooks and T. Kirkwood for valuable discussions.

\section{References}

Artett, C. F., Harcourt, S. A. and Broughton, B. C. (1975). The influence of caffeine on cell survival in excision-proficient and excision-deficient xeroderma pigmentosum and normal human cell strains following ultraviolet-light irradiation. Mutat. Res. 33, 341-346.

Bravo, R., Frank, R., Blundell, P. A. and Macdonald-Bravo, H. (1987). Cyclin/PCNA is the auxiliary protein of DNA polymeras delta. Nature, Lond. 326, 515-517.

Bravo, R. and MacDonald-Bravo, H. (1987) Existence of two populations of cyclın/proliferating cell nuclear antigen durıng the cell cycle. Association with DNA replication sites. J. Cell Biol. 105. 1549-1554.

Brooks, R. F. ANd Riddle, P. N. (1988). Differences in growth factor sensitivity between individual 3 T3 cells arise at high frequency: Possible relevance to cell senescence. Expl Cell Res. 174, 378-387.

Collins, M. K. L. AND Rozengurt, E. (1984a). Homologous and heterologous mitogenic desensitisation of Swiss 3T3 cells to phorbol esters and vasopressin: Role of receptor and post-receptor steps. $J$. cell. Physiol. 118, 133-142.

Collins, M. K. L and Rozengurt, E (1984b). Insulin induces a selective heterologous desensitisation of the mitogenic response of Swiss 3T3 cells to vasopressin. Expl Cell Res. 151, 396-407.

Cristofalo, V. J. and Sharf, B. (1973). Cellular senescence and DNA synthesis. Thymidine incorporation as a measure of population age in human diploid cells. Expl Cell Res. 76, 419-427.

DiNardo, S., Voelkel, K. and Sternglanz, R. (1984). DNA topoisomerase II mutant of Saccharomyces cerevisiae: topossomerase II is required for segregation of daughter molecules at the termination of DNA replication. Proc. natn. Acad. Sct. U S.A. 81, 2616-2620

Earnshaw, W. B. AND Heck, M. M. S. (1985). Localization of toporsomerase II in mitotic chromosomes. J. Cell Biol 100, 1706-1715. Gerdes, J., Schwab, U., Lemke, H. and Stein, H. (1983). Production of a mouse monoclonal antibody reactive with a human nuclear antigen associated with cell proliferation. Int J. Cancer 31, 13-20.

GratzNer, H. G. (1982). Monoclonal antibody to 5-bromo- and 5-iododeoxyuridine: a new reagent for detection of DNA replication. Science 218, 474-475.

Grove, G. L. AND Cristofalo, V. J. (1976) Characterisation of cell cycle of cultured human diploid cells: Effects of ageing and hydrocortisone. J. cell. Physiol. 90, 415-422.

HaYflick, L. AND Moorhead, P. S. (1961). The serial cultivation of human diploid cell strains. Expl Cell Res 25, 585-621.

Inglot, A. D., Oleszak, E. And Kisielow, B. (1980). Antagonism in action between mouse or human interferon and platelet-derived growth factor. Archs Virol. 63, 291-296.

Loo, D. T., Fuquay, J. I., Rawson, C. L. and Barnes, D. W. (1987) Extended culture of mouse embryo cells without senescence: inhibition by serum. Science 236, 200-202

Macieira-Coelho, A., Ponten, J. And Philipson, L. (1966). The division cycle and RNA synthesis in diploid human cells at different passage levels in vitro. Expl Cell Res. 42,673-684.

Paulsson, Y., Bywater, M., Pfeiffer-Ohlsson, S., Ohlsson, R., Nilsson, S., Heldin, C-H., Westermark, B. and Betsholtz. C. (1986). Growth factors induce early pre-replicative changes in senescent human fibroblasts. EMBO J. 5, 2157-2162.

Ponten, J., Stein, W. D. and Shall, S (1983). A quantitative analysis of the ageing of human glial cells in culture. J. cell Physiol. 117 $342-352$.

Prelich, G. and Stillman, B. (1988). Co-ordinated leading and lagging strand synthesis during SV $40 \mathrm{DNA}$ replication in vitro requires PCNA. Cell 53, 117-126.

Rittling, S. R.. Brooks, K M., Cristofalo, V. J. and Baserga, R. (1986). Expression of cell cycle-dependent genes in young and senescent WI-38 fibroblasts Proc, natn. Acad. Scl. U.S.A. 83 3316-3320

Shall, S. (1987). Mortalization or reproductive sterility of anımal cells in culture. In Perspectives on Mammalian Cell Death (ed. C S. Potten), pp 184-201. Oxford University Press, Oxford.

Shall, S. AND STEIN, W. D. (1979) A mortalization theory for the control of cell proliferation and for the origin of immortal cell lines. $J$. theor. Biol. 76, 219-231.

Smith, J. R. AND Hayflick, L. (1974). Variation in the life-span of clones derived from human diploid cell strains. J. Cell Bıol. 62, 48-53.

Stein, W. D., Eluls, D. and Shall, S. (1978). A mortalization theory for the control of cell proliferation and for the origin of immortal cell lines In Cell Reproduction (ed. Dirksen, E. R., Prescott, D. M. and Fox, C. C.), pp. 147-154. Academic Press Inc., N.Y.

Stein, W. D. AND Shall, S (1978). A stochastic model generating a constant rate of cell production from a population of dividing cells. $J$. supramolec. Struct Suppl. 2324. 
Uemura, I. And Yanagida, M. (1984). Isolation of type I and II DNA topoisomerase mutants from fission yeast: single and double mutants show different phenotypes in cell growth and chromatin organisation. EMBO J. 3, 1737-1744.

Vogel, A., Raines, E., Kariya, B., Rivest, M.-J. and Ross, R. (1978),

Coordinate control of 3T3 cell proliferation by platelet-derived growth factor and plasma components. Proc. natn. Acad. Sci. U.S.A 75,

2810-2814.
Westermark, B. (1978). Growth control in miniclones of human glial cells. Expl Cell Res. 111, 295-299.

YaNG, L., Wold, M S., LI, J. J., Kelly, T. J and LiU, (1987)

Roles of DNA topoisomerases in simian virus 40 DNA replication in vitro. Proc. natn Acad. Sci. U.S.A. 84, 950-954.

(Recelved 25 May 1990 - Accepted 20 July 1990) 